\title{
Urban Individual Households and Cultural Change in China: When "Losers" Become "Winners«
}

OLE BRUUN

Studies of China's urban individual sector have overwhelmingly focused on its economic significance. ${ }^{1}$ This study explores the degree to which the urban private economy has also been able to affect a substantial value transformation, and the way urban private households have influenced modern Chinese society generally. Neither totally free nor totally controlled, China's individual households are in a unique social position. Based on fieldwork in Chengdu, Sichuan Province, as well as additional observations in other major Chinese cities, this paper will not only argue that a profound transformation of values is taking place, but also that this trend is rapidly accelerating. Nevertheless, this process may reveal certain immanent features of Chinese tradition: namely, the oscillation between contradictory interpretations of essential ideals. ${ }^{2}$

Since private enterprise was reestablished at the Third Plenary Session of the Chinese Communist Party, in December 1978, the entire appearance of Chinese cities and towns has changed profoundly. Chinese policies regarding the private sector reflect the deep ambivalence in which the regime finds itself. Reaching far beyond the classical contradiction between political idealism and economic pragmatism, the official attitude towards individual business, and the fact that individual entrepreneurs are becoming wealthy, expresses Chinese cultural values which are far more significant than the dogmas of Marxist theory. However, before developing this argument, I will recapitulate the three stages through which private enterprise has developed during the last decade.

1979-82: This period saw the legalization of a number of businesses already in existence, including the integration of semi-clandestine activities into the formal economy. People previously living and working in the shadow of established society became registered in this new "third category" of employment. The slow growth of private enterprise in this period was more likely caused by the hesitation of potential entrepreneurs who were checking the stability of the new policy rather than the insufficient attraction of private business. 
1982-87: Rapid development of private enterprises due to flow of individuals from temporary employment, collective units discharging surplus labour, retired workers seeking extra income, former convicts having no other choice, etc. The new entrepreneurs in this period belonged primarily to marginal groups in Chinese society, groups situated outside the formal hierarchy of employment. In addition, a large number of housewives or individuals in low-paying jobs, but with spouses placed in secure positions, launched businesses on their own to supplement family income. Entire households making the leap into private employment were few, presumably an expression of the caution produced by historical experience.

1987-1989: The stability of state policies towards private enterprise combined with China's economic recession generated a new wave of people transferring to private employment. Contrary to the previous periods, however, the recent stage is marked by an increasing number of households breaking their connection with the state and with collective units to become entirely self-employed. Moreover, those who break their links to formal positions consist no more of the marginal groups, but of an increasing number of people from the social core of Chinese society: ordinary factory workers, shop assistants, lower cadres, etc. Private business has become accepted by common people as something more than a last resort when everything else fails; although values only change slowly, private business has increasingly become considered as a possible occupational strategy. The success of a few wealthy entrepreneurs has now provided an example to the many, especially to the mass of workers in unsuccessful state and collective units that are unable to make wages keep pace with inflation. However, important social differences may stem from the increasing regional differentiation now acknowledged by the central government. Especially the inner provinces, such as Sichuan, have experienced economic setbacks that are likely to stimulate the transfer of the labour force to individual employment, and the official policy of creating a limited labour market to replace the "fenpei system has certainly been pushed ahead in the interior.

Chinese statistics indicate only vaguely the true significance of the private 'sector. Recent nationwide figures (1987) show a total of 14 mill. businesses, employing a total of 21 mill. people. ${ }^{3}$ My own field data suggests, however, that private business, at least in the urban economy, influences the lives of a far greater number of people. ${ }^{4}$ The continued efforts of 
Chinese authorities to use statistics in support of adopted policies will be discussed later in this paper.

\section{The Informal Hierarchy}

The return of private business broke the State and Party monopoly on the allocation of positions in a formal hierarchy of employment. It created an alternative to the formal career path, where discipline often overshadowed skills and knowledge. The appearance of an sinformal hierarchy" dominated by purely materialist aims may indicate how the Chinese have resuscitated a dynamic element of traditional society: the interplay between competing hierarchies providing either prestige with no direct access to wealth, or, wealth accompanied with very low social esteem, ${ }^{\overline{5}}$ and leaving it to the individual to gain the universally desired balance between the two by transforming one into the other. This dual hierarchical system, although providing real choice to a few, nevertheless implied competing interpretations of Chinese values and separate roads in the struggle for power in local communities.

The meager official wage characteristic of formal positions in traditional Chinese society has been replicated in modern China. It took but a few years for the private sector to generate millionaires, even from extremely simple activities, ${ }^{6}$ thus revealing the utterly inefficient operation of state units, especially in commerce and service. Today, even high-ranking officials in local society see their wages being exceeded by the income that, for instance, an old illiterate woman can gain from selling cigarettes in the street. Moreover, the gap between state wages and private business profits continues to widen. The situation is apparently becoming more grotesque, as a large number of state employees see the purchasing power of their wages decrease drastically. ${ }^{7}$ However, Chinese private business comprises economic activities that only in a Chinese setting are regarded as belonging to a single category. The category of geti $h u^{8}$ covers anything from an elderly woman who sits in the corner of her compound repairing a few hand bags for friends and neighbours for a survival wage to the ambitious industrialist or restaurant owner who has considerable capital and a high number of employees under his command. ${ }^{9}$ My own field data shows household profits ranging from about 40 Yuan to approximately 5000 Yuan per month in a single street containing 150 businesses $^{10}$, compared to the average state wages of under 100 Yuan per month. In the 
area covered by my fieldwork especially restaurant owners could reach formidable incomes with just moderate investments, but all branches of the individual economy contained businesses that paid back investments in the matter of a few months, whereafter pure profits of $500-1000$ Yuan per month were yielded.

Yet it appears that the category of individual households (geti $h u$, which semantically is a non-category) has only limited economic significance as it encompasses activities of great diversity and little internal consistency. Far more important are its social implications, as it designates households outside the ordinary state and collective units (danwei) of life and work. In the Party idiom, staying outside always meant rebelling against the formal order of society. This is the connotation that the geti hu concept still holds to common people; it is closely linked to an inferior social position and often associated with criminal activity. Until recently, the transition to private business meant loss of dignity for the sake of money. Yet the new entrepreneurs have taken revenge for the disdain with which they have been treated. They have become the nouveau riches of Chinese society, and great numbers of them have totally outdistanced the standard of living that the vast majority of people have had to endure. As the whole economy is still oriented towards providing basic subsistence wages to state and collective workers, anything in excess of this level can be spent on additional consumption.

Although private business is practiced on varying levels, only a small minority of mainly elderly people achieve profits below the wages of an average worker. Most individual businesses earn profits which are several times this amount. At the highest levels, all Chinese cities now have scores of people that have rendered ridiculous the Chinese concept of a $» 10,000$ Yuan Household, " the equivalent of a millionaire, as their monthly profits easily exceed this. They are typically engaged in purely commercial business such as long distance trade, often with foreign products, trading clothes, steel and building materials, medical herbs, or they operate as brokers for large enterprises. The successful businesspeople now constitute a separate stratum in society; low in formal status, but with a huge capacity for consumption: Japanese motorbikes, American cigarettes (a pack of which would cost a worker several days wages), restaurant meals which would cost the loyal state employee up to a full months wages, and privately owned flats with expensive Western-style furnishing and fully equipped with Japanese electronics. This new stratum has created a mar- 
ket for human labour and services: anything from countryside maids doing household work for the wealthy to simple prostitution, which flourishes in this new environment. Any discussion of social status is now met by the entrepreneurs with remarks like, »He who has the money is now the King. ${ }^{11}$

The consciousness of class (jieji) and social position (shehuidiwei/shenfen) is still profound in Chinese society. ${ }^{12}$ Classification of entire households rather than individuals keeps each family member responsible for the performance of the whole group, and the group responsible for the activities of each of its members. But along with modernization an immense individualism is emerging among the new generation, to whom private business is frequently seen as a means of emancipation from the control of elders. As previously described, entrepreneurs have hitherto come from marginal groups, whose levels of education and common manners caused them to be stigmatized as the "lowest people" in society. According to established values not only occupation, but also secondary expressions such as language, clothes and manners are indicators of an individual's level of culture (wenhua shuiping). In the traditional unified structure of hierarchical positions, this is almost tantamount to social status level. Whether they react against established values, or just follow their own, it seems to be a general pattern that people living in a marginal position in relation to the formal society often express a total rejection of the "ideal "Chinese categories of social order, culture and moral standards. The young entrepreneurs tend to live exclusively in a world where anything new in regard to commodities is seen as "modern, " and anything different in regard to social behaviour is taken for »Western, " which only confirms mainstream Chinese prejudices against Western culture. The reckless extravagance of consumption of the nouveaux riches is frequently coupled with an utterly selfish attitude in social behaviour.

The ideology regarding social position is nevertheless deeply embedded in the minds of even the new »kings of consumption. «This becomes evident when compared to those private businesspeople who possess both wealth and a certain measure of social prestige derived from their previous occupation or level of education; e.g. retired cadres, demobilized army personnel or those with university degrees who have given up their assigned jobs. People from these groups, now well represented in the urban individual sector, tend to display quite different patterns of consumption: at least in public, they tend not to exhibit wealth in excess of the 
ordinary, and they also adopt longer-ranged strategies in their business investments. The average businessman, with little or no education and no prospects of ever reaching a level of culture that equals his economic capacity, displays his wealth as a means of compensating for his inferior social position. A local saying in the area of fieldwork held that uthose who are really wealthy always hide it - which may indicate that a few of the wealthiest people in the local society have a formal position.

The study of Chinese individual business is simultaneously the study of contradiction between central government and local authority, and the conflict between the sideal and the actually adopted practice. The huge discrepancy between these, and the fact that the gap may even be widening, is a crucial factor in any discussion of values in connection with private business. The practices of local authority are a strong conservative force in the ongoing reforms, and what is even more important, a massive impediment to the social changes following in the wake of economic liberalization. Furthermore, some authorities' abuse of power nourishes the steady disintegration of moral standards.

Ambivalence from above has facilitated corrupt practices at the local level. The central government's encouragement of private business is accompanied by restricted access to raw materials, credit, housing, labour, and social security, as the state attempts to protect a public sector of highly questionable efficiency. As the construction of a satisfactory legal basis for private business has not been accomplished, ample opportunity has been left for local interpretation and deliberate distortion of its intentions. The highly compartmentalized local bureaucracy has usurped nearly absolute power over private businesses; several independent authorities all have the power to close down a business if their claims are not satisfied. In the area where I conducted fieldwork, the Street Committee, the Industrial and Commercial Bureau, the Public Security authorities, the Health Inspection authorities and the Tax Bureau all had their own ways of extracting money and services from private businesses. Receipts were usually issued on sums paid, but as one informant said, »Anyone can buy a block of receipts and a rubber stamp. « Private businesspeople, in contrast, had no possible means to check the legality of the local authorities' actions. Neither does there exist any local media willing or able to follow up their complaints. Individual entrepreneurs remain impotent against what they describe as "too many mother-in-laws ${ }^{13}$ to care for.

The economic backlash in the inner provinces during recent years and 
the resultant lower bonuses in trouble-ridden state units have caused a general tendency toward personal solutions to economic difficulties. In the cities it is a common saying that "each has his way. "This is also the case with officials from the various bureaus in charge of private business; the period from 1987 onwards has brought new taxes, surcharges and fees to businesses. In the area of my fieldwork, supplementary fees, in addition to the business tax paid to central government, have doubled or tripled in this period, and the number of bureaus collecting them has increased from five to approximately ten. For the smaller businesses the additional fees now exceed the basic tax. The individual sector has become the happy hunting ground for the »uncrowned kings $«{ }^{14}$ of local authorities who use every possible means to extract more money. The whole picture has an increasing similarity to certain state units where many live on the work of a few.

The rising contradiction between the bureaucracy and the individual households and the consequent decline of moral standards is more than a result of simple personal profit-making. Very common is what the individual business- people call the "red eyes disease, "mere envy, ${ }^{15}$ from neighbours and officials. It is a very straightforward expression of the frustration directed by those with high formal position and low income towards businesspeople. Frequently it consists of accusing the more fortunate people of misdeeds, rather than analyzing the cause of one's own situation. Many examples were recorded among ordinary people exploiting power they had to extract money from businesspeople. But it was especially the case with officials in higher posts who found it impossible to accept a situation where the distribution of wealth does not follow social rank and prestige in society. Local authorities tend to counteract the ongoing social transformation in two ways. First, in their professional handling of affairs concerning private business they tend to interpret regulations with a view to hinder the rapid expansion of businesses. ${ }^{16}$ The control they execute is frequently social rather than economic, in that they create obstacles to businesses headed by individuals that do not accept the absolute authority of their bureau. Secondly, the individual officials tend to regard their position as a privilege rather than a profession; a privilege that can be exploited in every way that circumstances permit. Since private businesses in general belong to the lowest strata of society, they are the easiest to exploite. Apparently, the characteristics of Chinese bureaucracy as noted by Max Weber at the turn of the century are basically reproduced: 
the rejection of professional specialization in a modern expert bureaucracy and the related Confucian ethic rejecting «cultured man« as a tool in the economic rationalization of society. ${ }^{17}$

\section{The Media}

Whereas the Central Government-controlled media tended to encourage private enterprise until the June 4 events, and often tried to lure people with rose-coloured success stories, the local Party-controlled media has generally remained at best skeptical, and frequently downright hostile to the individual households. This was for instance the case in an article on the front page of the Chengdu Evening News ${ }^{18}$ in the spring of 1989, entitled "We Cannot Allow Them to Get Rich through Tax Evasion. «The article employed unusually harsh Cultural Revolution rhetoric and generalizations, stating that "many individual households have developed from investments of a few tens or a few hundred Yuan and now own assets of several tens of thousands, several hundred thousand, up to one million Yuan. But their tax payments have not increased with the same speed. « The article maintains that the average monthly taxes paid by individual households in Chengdu are only 31 Yuan. After mentioning that a famous mosquito net producer in Chengdu nicknamed "one million Yang «now owes more than 150,000 Yuan in back taxes, and that another well-known entrepreneur evaded taxes of over 90,000 Yuan, the article discusses the problems of the tax authorities. An unnamed tax bureau official states that "practically $100 \%$ of the individual households evade tax (tou lou shui), tax evasion is at least $70 \%$. The businessmen even have a saying which goes: If you want to get rich, just snatch the tax (chi shui). «The article ends by referring to a new Shanghai initiative aimed at exposing tax evasion: "Should not our city employ similar measures? « the article asks.

To evaluate properly the message of such an article, some basic facts must be considered. First, in 1989 tax assessments in individual businesses were still not based on accounts, but on the tax officials' own estimate of the turnover of every business. Tax officials have the final word and there is no possibility for businesspeople to complain. Secondly, in December 1988, taxes were increased by $50 \%$ all over Chengdu simply by increasing the estimated turnovers of all businesses. Thirdly, the situation for small businesses in Chengdu is that uncontrolled charges paid to local bureaus exceed tax; if average taxes are only 31 Yuan as stated by the paper, 
the total fees for an average individual business are far higher (50-100 Yuan). In the area of my fieldwork, for example, the monthly "security fee« paid to the local police station ( $p a i$ chu suo) (one of such 8-10 fees) averaged 15 Yuan. Fourthly, my own field data indicate that tax evasion among small businesses is limited, while the bigger businesses have better means of lowering their taxes by using their guanxi (connections). Other details in the article mentioned above deserve comment. The mosquito net producer mentioned probably no longer owns a purely private business. People from his neighborhood claim to know that he was forced to convert his business into a joint state-private enterprise, as he was becoming "too powerful. «On the level of local gossip, which provides a substantial part of all information in Chinese cities, tax officials are in a dubious position when criticising private businesspeople: despite their very low official wages they are generally considered to be wealthy.

Apart from providing some basic figures on private business, such articles obviously present a highly distorted picture. However, the sub-contextual message may be the most important, as it presumably represents the attitude that the Party organization had already then adopted towards private business. Such articles constitute clear signals to local authorities and to businesspeople. To the bureaus in question the article emphasizes support for their practices, and even gives the green light to proceed further. To businesspeople these writings deliver a warning that local authorities will be strengthened and that the recent development of local power at the expense of central government, even where it entails disregard of new regulations, has the backing of the Party organization. Local media help justify the display of force that businesspeople experience from the officials they depend on for operating permits and for maintenance of their legal status. Obviously, the control that the Party attempts to impose on businesspeople is of a traditional type: it supports its own members' illegal practices in order to avoid what is worse; i.e. it prefers predictable lawlessness to the unpredictable consequences of a new stratum's rise to power. But in either case the actual control that the CCP has over local community economic life appears limited.

In a broader social context, the writings of the Party controlled media, put forward at a time when many state employees are experiencing a decrease in the purchasing power of their wages, may strike a public response. Accusations of creating inflation are often directed towards private businesses, since in most areas they are free to set their own prices. 
The local media have thus attempted to inflame public opinion by confirming prejudices, as well as constructing new ones, against private businesses. In the Party line of thought ${ }^{19}$ the causes for the success of private businesses in general are that sthey get rich through swindling and tax evasion«; the positive impact of higher efficiency is largely ignored. These accusations thus touch the widespread frustrations among state employees, and tend to direct aggression towards individual businesses by insinuating that they contribute to, or are even responsible for, China's present economic difficulties. Far more realistic, however, are worries expressed in Party circles that the rise of private business represents a threat to the leading role of the Party. When a growing number of households leave their danwei to launch private businesses, Party power evidently declines. Local authorities may be able to infringe on the entrepreneurs' profits, but not to control their lives. The monopoly on information that the Party has established for itself also indicates that the local level Party organization is unable to engage in a dialogue with informal groups. Local level authorities, in the words of businesspeople, »do not tolerate one sentence of critique. "Conversely, the media direct their critique downward, towards the people who cannot defend themselves publicly. Private businesspeople are barred from expressing their views: as they generally complain: "We have no one to speak for us. ${ }^{20}$

\section{Transformation of Values}

Whether or not private entrepreneurs are seen as a threat to the established order, significant social transformation is nevertheless taking place, although strong interests may dampen it. A crucial factor in this process is the challenge that private business poses to established post-Liberation values, according to which conformity is rewarded, belonging to a unit is a rational strategy, and formal authority is the obvious path to privileges. In a society with thoroughly controlled communication on the national level little variation has developed in terms of interpretations of common values. It has become obvious that some of the lowest people in regard to social position have become wealthy, and, in a certain sense, privileged. When private enterprise was legalized it was under slogans such as »We must allow some to get rich before others, " which is often referred to as "the fat pigs' policy. «From historical experience there have emerged popular sayings such as »People fear getting famous like pigs fear getting 
fat. ${ }^{21}$ Relatively stable conditions and continued encouragement to take the private road have had great effects. When reforms were instituted, many people found it was the wrong people who got rich first: peasants, ex-convicts, illiterates, social outcasts etc. Subsequently, other groups became increasingly impatient waiting for »their turn « to get rich. In recent years, more and more people have apparently realized that waiting is most likely to be in vain.

Transfer to private individual business is commonly accompanied by a fundamental reorientation of priorities by the households and individuals concerned. As a social force this appears as a gradual transformation of values. According to my fieldwork material, comparison between what people in state employment and individual business mention when asked about the main attractions of their work, formed two distinct patterns. People in state employment however seemed a more homogeneous group, whereas considerable variation was evident in the motivations for starting private business. State employees typically stressed the »dignity a and "prestige « that their work brings to the household in relation to friends and neighbours. "Higher social position« and »respectability« gained in relation to the wider society is another very important aspect of state employment. "Security" is mentioned as a feature of fundamental importance, and is for many the very reason for maintaining their positions. In connection with the nature of the actual work involved, qualities mentioned were its »clean « (often non-manual) and noble character. State units often satisfied this criteria by making sure that employees were able to return home every day with no traces of having performed hard or filthy work. Here one detects a strong drive towards avoidance of manual labour, although this in general was expressed only indirectly. Yet one of the essential qualities of state employment may be the desire to conform, to be a prominent member of society. These ideas will be discussed in the conclusion.

Running the risk of oversimplification, the transformation of the elements contained in this pattern will be suggested here. Although elements of a value system representing orthodox social thought, the individual concepts applied to social values constitute highly complex entities related to history as well as the general conditions of modern Chinese society.

The transformation of the value termed as security is probably the most obvious and straightforward among these elements. Leaving the danwei implies great risks, socially as well as economically, as neither health care, 
pensions nor housing benefits are granted to households outside such organizations, and generally there is no possibility of returning. Thus, the functions of the danwei can only be replaced by money, as all necessities and services must be purchased. Quick profit-making is seen by most households as a solution to the problem, often at the expense of business consolidation. Historical experience evidently puts a limit on what people will sacrifice for long-term planning, but far more important are probably certain elements of traditional Chinese business mentality pointing in the same direction. The fact that the old Chinese society, which was totally dominated by small-scale private business, existed only a single generation ago, and the fact that a large proportion of present-day shopkeepers actually have small business backgrounds have contributed to a rapid transformation from the praising of job security in spite of poor pay to the hailing of quick profits in spite of no social guarantees.

The social status of households that venture into private business inevitably drops. Although businesspeople tend to form a hierarchy among themselves, their position in this informal hierarchy carries little prestige or recognition among members of the formal hierarchy of state employment. Neither does material wealth gained from individual business in itself have any impact on the social status of the household. In the general division of strata in society they belong to the lowest. The common consensus in this field often runs contrary to central government policies and it has hitherto been a strong conservative force in the development of the private sector. Compensation for lost status through conspicuous consumption is admitted by many businesspeople themselves. The social inferiority that they feel not only stems from abstract ideas about social class; the patronizing attitude of a large section of their customers are additional everyday reminders of their position. In relation to local authority, businesspeople experience that social position has concrete implications in terms of power, or the lack of same, as serious discrimination is practiced by most administrative bodies. They strike back in the domain in which they are superior, the domain of consumption. The material wealth that they are able to display is intended to redress the imbalance - especially when directed towards the ordinary state employee, who despite his dignity has become one of the poorest among city dwellers. The expensive pastimes in which even basic level entrepreneurs can indulge are a powerful means of mocking the state employee's naivieté. The open display of wealth is a source of conflict and grudges in local society, and particularly 
officials tend to take this into consideration when handling local affairs. However, showing off one's wealth is another aspect of private business where traditional values strike through, highlighting the extreme sociocentric orientation in Chinese culture.

The dignity derived from official employment may not be transformed directly into a quality which private employment also has, and which is in greatly increasing demand in society at large, but it compares well. This is the social freedom and self- determination that private employment offers, and which is an obvious advantage over state employment. Renouncing one's dignity in relation to formal society for the sake of gaining more personal freedom is not solely associated with private business. Especially in times when the formal order of society is in crisis, this kind of trade-off is seen by many as acceptable. It also signifies a general trend in society towards individualization; a strong desire for emancipation from controlling authorities within the family, in work units and in public life. Although the young generally are the first and most daring in this process, they tend to lead the way for a number of others.

The state employees' emphasis on the quality of work which is clean and noble is closely related to the private entrepreneurs' struggle to become bosses of their own businesses. Divorcing themselves from manual labour, which is usually left to rural employees and, ultimately, from all the major tasks of business are typical ideals for shopkeepers. Even in an early stage of development they frequently leave the day to day business operations to employees or other family members, while themselves engaging in guanxi-making, trips to town, socializing, etc. Many shopkeepers are able to get by with just purchasing goods for the shop in the morning and clearing the cash box at night. This was especially the case with male shopkeepers and frequently represented a serious impediment to the sound development of business. Female shopkeepers tended to have a higher degree of participation in the actual work. Thus, the wealth and authority over employees that the successful male entrepreneur achieves becomes a manifestation of his power, which he attempts to extend in outward relations, parallel to the struggle among cadres for authority in the formal hierarchy. Related to these ideals is also the low esteem in which crafts are still held. As engaging in crafts not only requires long training, but also the continuous participation of the master craftsman in business, it is a considerably less popular branch of the urban individual economy, particularly among the youth. 
The last of the value complexes mentioned initially is also the most essential to cultural change. From conforming to the rules and discipline of the danwei to embarking upon the individualist venture of private business is a dramatic shift. It involves a degree of rebellion against the formal order of society, and surely runs contrary to the social thought propagated by the Party organization. Although private enterprise is encouraged by the central government, it may not be equally approved by local institutions. In fact, the danwei often constitutes the greatest obstacle to those wanting to start their own businesses, inasmuch as skilled personnel was until recently not given permission to leave their jobs. Change in policy has made it possible for more people to take the "private road, «but it has not necessarily made it any easier. The educational level greatly influences the expectations of the individual, not only in the danwei, but also in the larger society. For the illiterate, elderly, disabled, former convicts and other low social status categories, joining the individual economy may be seen as natural. Craftsmen with rather basic education can also be expected to start private businesses, as was the tradition in pre-Communist China. According to Chinese social classifications, private small businesses are linked to the social categories of poor education, inferior social position, insignificant power, and no access to privileges. If, however, someone with high education and high position in the formal hierarchy, or prospects of such, seeks to transfer to private employment, it is seen as social deviance, and often arouses suspicion. Departure from established custom in this field can thus be interpreted as a shift from conformity to rebellion against some fundamental Chinese worldviews.

Returning to the capacity for cultural change in the private sector, these classifications are crucial. Whereas the economic significance of the private sector may still be limited, its social impact is enormous. The real potential for change in Chinese society lies in the challenge of the private sector and its affiliated value system to formal society. The existence of a successful private sector indicates that there are other paths to privilege than conformity, that an easy life can be attained without sacrificing personal freedom. It has provided an alternative framework to the wages and living standards in the danwei and stimulated new thought about the old concepts of repression and exploitation. Furthermore, the success of the private entrepreneurs has shaken the whole educational system by making it obvious that very basic schooling suffices to become wealthy, and that all additional education is either fruitless or at best a very doubtful 
investment. In a more spiritual sense, the success of private entrepreneurs has proven that in spite of the glorification of collective work in recent decades, a small niche of free enterprise could release the human energy and the work ethic long desired in the siron bowl«type of organizations.

In relation to formal society, the individual economy can hardly be said to offer any separate life style, ideology or organized alternative. Comprising a wide range of people as well as businesses, it exists only as a category in itself insofar as it is non-public. It exists within a monolithic society with little tolerance of deviation. If certain patterns can be identified with regard to the way private entrepreneurs relate to the rest of society, it is a question of reacting to a common influence rather than having a common aim.

The individual sector nevertheless constitutes a powerful source of stimulation to ordinary people. It arouses their indignation and simultaneously nourishes their desire to break out and try for themselves once circumstances permit: »if others can gain from being 'selfish' individual households, we can do the same. "The example that private entrepreneurs sets has not only caught the interest of the media, but has also become a major topic of discussion in work units, within the family and at social gatherings. It has created an alternative in peoples' minds, and has involved a large part of the city population in a spontaneous and selfreproducing process which if allowed to continue could lead towards the final rejection of the solemn self-sacrifice demanded in the danwei.

Nevertheless, as discussed above, strong forces oppose the free and spontaneous flow of social energies. Predominant is the monopolization of power by central as well as local authorities, who struggle to exercise absolute authority by extinguishing and preventing all opposition. While this trend is most obvious within the Party organization, it is nevertheless equally significant within the lowest level of bureaucracy. Contrary to the kind of economic control generally recognized as beneficial to the private economy, it is frequently social control that is practiced at the local level. Local authorities tend to crack down with more vigour on extravagantly behaving individuals and households than on local profiteers, forgers and swindlers. Control is lax as long as taxes and fees are paid, and lawbreakers are often seen as an extra source of income by the officials. ${ }^{22}$ The local bureaucrats demand only that their authority and power be recognized, and that no critique be made of their practice. The parallel between higher and lower levels of bureaucracy shows the true significance of this 
power-monopolizing type of thought, essential to the structure of Chinese authority.

\section{Conclusion}

Before June 1989 individual enterprise was becoming increasingly attractive to urban residents, in absolute as well as in relative terms. Contrary to earlier periods, the individual sector was joined by an increasing number of ordinary state and collective workers who definitively severed their ties to their former units. Their breaking off from the tightly organized units constitutes a significant trend in Chinese social and cultural developments. Socially, it marks the transition to a civil society, which implies a gradually changing power structure. Culturally, it may sow seeds of rebellion against the monolithic society and facilitate the growth of heterodox thought. Together with other movements in Chinese society, this may be the beginning of the end of an era in Chinese history.

Along with this social transition, a shift in values is also taking place. Whether this marks a shift back to traditional values, to traditional strategies applied to a new situation, or can be regarded as entirely new ones, is a matter of definition. The concept of "tradition « tends to be purely abstract in the Chinese context, as it generally refers to "ideal « culture, or "ideal" behaviour, representing a model rather than social realities. Chinese history has proven that these concepts can be interpreted, manipulated or articulated in multiple ways, all of which indicate the tradition to be upheld and Chinese in its character.

From an anthropological point of view, the question of conformity contra rebellion is of major importance, as it appears to be crucial to explaining the dynamics of Chinese culture; from small community level to the highest authorities some basic, underlying structures can be traced. The demand for conformity remains strong at all levels of social interaction, and all dissidence tends to be stigmatized by the majority. However, where individuals succeed in breaking out and prove themselves by extraordinary achievements, they are easily turned into heroes. He or she becomes an example to follow. The private entrepreneurs in China in the 1980's were experiencing the gradual change from being social outcasts to becoming the new heroes of development. What their role will be in the 1990 's naturally depends on the dynamics of Chinese politics. But the private sector has certainly manifested itself as a social force that the regime has to take into consideration. 
While values and strategies of attaining the "good life « are changing, this has inevitably created increasing social tension. The power structures at local as well as at central levels leave little room for spontaneous social development. The small elite, holding entirely monopolized power, seems unable to accept the social revolution following in the wake of economic reforms. Hence, any social development in a Chinese setting is most likely to necessitate confrontation, producing radical upheaval rather than steady development to the benefit of the majority.

The latest revolts in Chinese cities, and the violent measures adopted by government, may have created a new situation for private enterprise. In a general crackdown on all heterodox thought and potential opposition, individual households will inevitably attract the attention of the ruling authorities. ${ }^{23}$ In addition, the private sector will be the last economic "refuge for individuals punished for counter- revolutionary activities. The latest proclamations from the central government are that the Open Door Policy will be continued, but signals are being emitted concerning stricter measures towards the alleged tax evasion in the private sector and the enforcement of regulations demanding taxation based on accounts. ${ }^{24}$ Moreover, a number of new taxes have been introduced. ${ }^{25}$ Although fairly neutral concepts are still applied to individual households, they have been conceptually encircled as the new middle class (zhongchan jieji). Thus, it only takes a simple transcription to turn them into defenceless scapegoats, as has always been dreaded by shopkeepers and as has earlier been the case in times of crisis when authorities needed attention to be turned away. Fighting against corruption has simultaneously been on the agenda. However, any correlation between the corrupt practices of the bureaucracy and the inadequate revenue collected from individual households still awaits analysis. In the meantime, Chinese authorities proceed to fight corruption by means of hypocrisy, while coping with economic stagnation by means of unrealistic projections.

Ole Bruun is a Research Fellow at the Institute of Anthropology and is associated with the Center for East and Southeast Asian Studies, University of Copenhagen. 


\section{NOTES}

1. E.g., Stanley Rosen, ed., "The Private Economy, "Chinese Economic Studies, Vol XXI, No. 1-2, 1987-88; Wolfgang Taubman \& Thomas Heberer, "Die Städtische Privatwirtschaft in der VR China - Second Economy zwischen Markt und Plan, "Bremer Beitrüge zur 8 Geographie und Raumplanung, Heft 14, 1988; Ole Bruun, "The Reappearance of the Family as an Economic unit: A Sample Survey of Individual Households in Workshop Production and Crafts, Chengdu, Sichuan Province, China, "Copenhagen Discussion Papers, No.1, December, 1988.

2 Research Project funded by the Research Council of the Danish International Development Agency. See above Bruun, "The Reappearance of the Family as an Economic Unit, " for an intermediate account of the research.

3 Beijing Review, 1989, No. 16. Renmin ribao, haituai ban, August 12, 1989 states that individuals in private business have increased by 3.6 million in 1988.

4 My field data indicate that a number of businesses and market vendors operated without licenses, or for various reasons were not included in official statistics, Also, the number of people involved in each business was far greater than the number officially registered. Chinese sources (e.g. China Daily) has estimated private business to encompass 60-70 million people, but even this may be conservative.

5 For a historical approach to the dual hierarchical system see S.A.M. Adshead, Province and Politics in Late Imperial China, Viceregal Government in Szechwan, 1898-1911 (London, 1985).

6 For an early account, see Linda Herskovitz, "The Fruits of Ambivalence: China's Urban Individual Economy," Pacific Affairs, Vol. 58, No. 3, 1985.

7 E.g. China Daily, April 20, 1988: Price rises and market swing bring problems and non-monetary benefits from official employment of course makes comparison difficult. However, in the area of fieldwork only the highest cadres had legal privileges worth more than their official wages.

8 Geti $h u$ means individual households. A distinction between individual households and private enterprise (siying qiye) with over seven employees introduced by central government in 1988 has still not been effected in Chengdu.

9 Bruun, "The Reappearance of the Family as an Economic Unit, « p. 49.

10 Bruun, "The Reappearance of the Family as an Economic Unit, « p. 115. Average profits stated: 280 Yuan; my own estimate was 450-500 Yuan.

11 "Xianzaishuiyou qian, shuijiu shiwang,"

12 Class as an absolute position in society is probably an alien concept in China. Rather it should be considered a relative position in a hierarchy of personal positions; e.g. Philip A. Kuhn, "Chinese views of social classification, " in J.L. Watson, Class and Social Stratification in Post-Revolution China (London, 1984).

13 "Popo tai duo le."

14 "Wu mian zhi wang."

15 «Hongyanbing. « E.g., »Hong yan bing chi ren. Dangdai geti hu. "Geti jingying 100 pian (Zhongguo Qingnian Chubanshe, 1987).

16 For instance by denying licenses for more than one activity in the same shop, or for one household to run more than one business, making it difficult to change type of business etc.

17 Max Weber, The Religion of China: Confucianism and Taoism (London, 1920), Chapter VIII, Conclusions.

18 Chengdu Wanbao, March 22, 1989.

19 As expressed in personal discussions with Prof. Li Daonan, Sichuan University and Associate Prof. Chen Li, 
Sichuan University, who were conducting research on the private economy for the Chinese Communist Party Committee in Chengdu.

20 During long periods of fieldwork this was the most frequent complaint from businesspeople. They felt powerless in regard to the unjust treatment by authorities.

21 «Ren pa chu ming, zhu pa chu zhuang, " a recent variation over a general theme in Chinese proverbs. Countless traditional proverbs express the danger of being »the leading bird " which is first shot or "the tallest tree " that falls in the storm, etc.

22 Shopkeepers guilty of breaking regulations were heavily overcharged by a number of local authorities for such infractions as using opium in the hot pots (huoguo), selling unauthorized tape re- cordings, "pumping up « chickens with water, having pornographic magazines under the counter, etc.

23 One of the latest examples is the campaign to wipe out pornography (sao huang yundong) in which 40,000 private entrepreneurs allegedly were arrested and 37 executed (Zhengming, No. 145 (October 16) 1989). In this campaign private businesspeople were accused of supporting the students during the demonstrations and even of selling arms.

24 E.g. Renmin ribao, haiwai ban, August 22, 1989; Renmin ribao, haiwai ban, September 4, 1989. Renmin ribao, September 6, 1989 mentions that the main problem is not the level of taxation, but its administration and collection.

25 E.g. Zhongguo shibao, October 23, 1989. 